УДК 378.016:33

DOI 10.18101/2304-4446-2019-2-58-65

\title{
СТРАТЕГИЯ ИНВЕСТИЦИОННОГО РАЗВИТИЯ ФОНДОВОГО РЫНКА: ТЕОРЕТИЧЕСКИЙ АСПЕКТ
}

\author{
(c) Осипова Гета Михайловна \\ доктор экономических наук, профессор, \\ Бурятский государственный университет имени Доржи Банзарова \\ Россия, 670000, г. Улан-Удэ, ул. Смолина, 24а \\ E-mail: getaosipova@mail.ru
}

В статье исследуется стратегия объективной необходимости инвестиционного развития фондового рынка в конкурентной среде. Изучена система научных взглядов на формирование категории «фондовый рынок» как в зарубежной, так и в отечественной литературе. Выявлено, что понятие «фондовый рынок», сформулированное зарубежными авторами, является более отвечающим реалиям рыночной экономики, ее неопределенности. Этот подход расширяет возможности для усиления роли фондового рынка в инвестиционных процессах. Эффективно действующая экономика невозможна без оптимально функционирующего фондового рынка, способного привлекать инвестиционные ресурсы. Предложены меры по усилению регулятивной инфраструктуры государства в области законодательства через разработку правил и установление требований к информации о лицах, являющихся конечными бенефициарами российских предприятий для снижения рисков и обеспечения спроса на эмитируемые финансовые инструменты; по совершенствованию налогообложения услуг, предоставляемых участникам финансового рынка; по оптимизации дивидендной политики в целях привлечения отечественных и иностранных инвесторов, в том числе розничных.

Ключевые слова: фондовый рынок; инвестиции; стратегия; рынок ценных бумаг; финансовые ресурсы.

\section{Для цитирования:}

Осипова Г. М. Стратегия инвестиционного развития фондового рынка: теоретический аспект // Вестник Бурятского государственного университета. Экономика и менеджмент. 2019. № 2. С. 58-65.

В рыночной экономике фондовый рынок играет важную роль в развитии страны. Он регулирует многие социально-экономические, финансовые процессы, в том числе аспекты инвестирования капитала и мобилизации средств населения. Создание эффективно работающего фондового рынка является одной из составляющих повышения уровня устойчивости и конкурентоспособности финансовой системы, привлечения населения к активному инвестированию своих сбережений в ценные бумаги. Для обеспечения притока инвестиций в реальный сектор экономики нужны меры стратегического государственного регулирования, способствующие развитию механизма оптимального функционирования фондового рынка за счет:

- развития внутренних институциональных инвесторов;

- повышения эффективности функционирования технической инфраструктуры фондового рынка;

- совершенствования двухуровневой системы фондового рынка; 
Г. М. Осипова. Стратегия инвестиционного развития фондового рынка: теоретический аспект

- для обеспечения инвестиционными ресурсами хозяйствующих субъектов государственная политика должна опираться на цели всемерной поддержки отечественного производителя, через доверие к фондовому рынку.

Вместе с тем наличие значительного объема свободных денежных средств у российских граждан, с одной стороны, и острая потребность в этих средствах у производственного сектора экономики - с другой, требуют оптимального способа привлечения средств мелких инвесторов в институты коллективного инвестирования. Это актуализирует создание системы эффективной защиты интересов инвесторов и предотвращение неопределенности, рисков, предотвращение кризисов в деятельности коллективных инвесторов.

Отрицательно влияет на развитие фондового рынка недостаточное количество квалифицированных посредников, способных обеспечить условия для привлечения средств населения. Не относятся к фондовому рынку как надежному средству размещения собственных финансовых ресурсов и предприятия. Они предпочитают не расставаться с контрольными пакетами акций, хотя реализация на рынке даже части пакета могла бы стать источником дополнительных инвестиций.

Вышеизложенное обусловливает объективную необходимость разработки и обоснования современной, учитывающей сложившиеся реалии на глобальном рынке, долгосрочной инвестиционной стратегии развития российского фондового рынка.

Стратегический взгляд на изменения в прошлом и будущем на фондовом рынке логически предполагает выявить факторы, определяющие развитие фондового рынка. Это, в свою очередь, требует определения содержания категории «фондовый рынок». Имеются различные взгляды на сущность понятия «фондовый рынок», методологические подходы к его исследованию и, наконец, на что мало обращается внимание - на мотивацию человека для осуществления вложений в ценные бумаги потенциальными инвесторами. Следует отметить, что при анализе происходящих различных процессов в российской экономической науке человек, его мотивация, психология поведения учитываются недостаточно, если не сказать - вообще не учитываются. В зарубежной экономической литературе человек как субъект рыночной экономики освещен в различных аспектах. Об этом свидетельствуют и общеизвестные труды зарубежных исследователей, в том числе лауреатов Нобелевской премии.

Далее системный финансовый анализ требует изучения путей совершенствования работы коллективных инвесторов фондового рынка, так как в современных условиях, по мнению автора, они могут стать потенциальными источниками мобилизации средств населения в экономику. «Например, зарубежные корпорации широко применяют такие модели финансового анализа, как система алгебраических уравнений, модель линейного программирования др. Результатом применения упомянутых моделей становится разработка прогнозов таких показателей, как курс акций, дивиденд на акцию, прибыль на акцию, планы по эмиссии акций корпораций и т. д.» [4]. Государство четко не определило границы своего вмешательства в механизмы фондового рынка, возможности повышения его конкурентоспособности в сравнении с другими формирующимися рынками. 
Для успешного решения вышеизложенных проблем необходимо выбрать из существующих методологических подходов к определению категории «фондовый рынок» такой, который отвечал бы реалиям неопределенности, рисков и конкретным специфическим условиям современного рынка.

Существуют различные методологические подходы к определению понятия «фондовый рынок»: традиционный, системный, функциональный, интегрированный и др. При таком подходе фондовый рынок рассматривается в основном как сфера деятельности, где сводятся вместе покупатели и продавцы фондовых ценностей (А. Буренков, В. Михайлов, В. Новожилов, С. Бир, П. Друкер, Г. Дефоссе, К. Девис, В. Торкановская, В. Колесников и др.).

Но есть и иные подходы. По мнению автора, наиболее удачным является методологический подход, при котором «фондовый рынок» - это не только функция купли-продажи ценных бумаг. Опыт зарубежных стран показывает, что фондовый рынок эффективного развития, с другой стороны, - важный фактор успехов в национальной экономике. Отличие фондового рынка от рынка любого другого товара - это то, что он служит формированию денежного капитала, а в дальнейшем становится одним из источников для инвестирования хозяйствующими субъектами в развитие производства или в приращение уставного капитала.

Исходя из такой аргументации более обоснованным является количественный, стратегический, ситуационный подход к сущности категории фондового рынка (И. Ансофф, Ч. Доу, О. Курно, Г. Марковиц, Д. Мэрфи, Б. Карлофф, А. Томпсон, П. Друкер, Г. Кунц, Ф. Фидлэр и др.). Такие подходы предполагают проведение количественных оценок при помощи математических статистических расчетов. Стратегический подход включает разработку направлений развития фондового рынка и принятия обоснованных решений при выборе способов инвестиционных решений. Вышеназванные исследователи обращают внимание на необходимость учитывать конкретную ситуацию на рынке, применяя различные модели фондового рынка. Изменились условия на рынке, меняются и конкретные цели, методы организации и регулирования фондового рынка. Инвестиционный климат подвергнут неопределенности, риску в зависимости от ситуации на внутреннем и внешнем рынке.

Тенденции развития фондового рынка потенциально демонстрируют наиболее вероятное поведение рационального рыночного игрока. Портфельный подход был развит в матрицах И. Ансоффа, Дженерал Электрик, Маккинзи и др. [1; 2; 3]. В настоящее время портфельный подход широко используется в стратегическом анализе на всех уровнях национальной экономики.

Исходя из вышеизложенного можно сказать, что фондовый рынок - это сложный организационно-экономический организм, состоящий из отдельных взаимосвязанных, взаимообусловленных между собой элементов. Эта система обеспечения производства товаров и услуг необходимыми инвестиционными ресурсами расширяет круг инвесторов, интенсифицирует денежный поток, обеспечивает процессы его распределения и перераспределения между отраслями экономики и предприятиями.

Как показал анализ, единой модели функционирования фондового рынка не существует, так как в каждой стране имеются свои специфические особенности в его становлении и развитии, что предопределяет необходимость учета историче- 
Г. М. Осипова. Стратегия инвестиционного развития фондового рынка: теоретический аспект

ского опыта, а также традиций, социально-политического и финансовоэкономических условий.

Важнейшим фактором в развитии и функционировании фондового рынка играет его инфраструктура. Известно, что инфраструктура - это организационноправовая система, действующая на основе законодательства и координирующая деятельность финансовых институтов на фондовом рынке. Инфраструктура фондового рынка представляет собой технологическую систему, использующую информационные технологии и представляющую совокупность каналов, обеспечивающих продвижение информации, инвестиционных ресурсов, прав собственности в экономическом пространстве данного рынка. То есть инфраструктура фондового рынка включает следующие блоки, по нашему мнению: регулятивную, консультативную, оценочную, технологическую, расчетно-клиринговую, учетную, информационную.

Управление формированием и развитием фондового рынка, направленное на его оптимизацию в условиях неопределенности и рисков, должно основываться на синергичности системы фондового рынка, когда одна направленность действий подсистем инфраструктуры усиливает эффективность функционирования системы в целом.

Важнейшую роль в системе играет законодательная инфраструктура. Нормативная правовая база в области рынка ценных бумаг постоянно совершенствуется и дополняется. Значимые изменения в законодательной базе произошли в 2017-2018 гг., в частности, сфере налогообложения на рынке ценных бумаг, деятельности профессиональных участников.

В Федеральный закон «О рынке ценных бумаг» в декабре 2017 г. были внесены дополнения о появлении в России института инвестиционных советников начиная с декабря 2018 г. Роль инвестиционного консультирования заключается в консультационных услугах в отношении ценных бумаг, сделок с ними и (или) заключения договоров, являющихся производными финансовыми инструментами, в предоставлении индивидуальных инвестиционных рекомендаций, соответствующих инвестиционному профилю клиента. Инвестиционные советники должны являться членами саморегулируемых организаций, но их деятельность не лицензируется.

Формирование в России института инвестиционных советников, будем надеяться, поможет резко увеличить количество человек, участвующих на торгах на рынке ценных бумаг. В настоящее время по данным статистики ученых их число составляет небольшую долю трудоспособного и финансово активного населения (1 процент). Общеизвестно, что в развитых зарубежных странах большая часть населения является участниками торгов фондового рынка.

В России, например, в системе торгов на Московской фондовой бирже по состоянию на 31 августа 2013 г. по сравнению с 31 августа 2017 г. число физических лиц увеличилось на 27,8\% (с 882528 чел. до 1224837 чел.), а иностранных лиц соответственно за этот же период — на 33,6\% (6 722 чел. до 10116 чел.) ${ }^{1}$.

В 2016 г. 52\% совершеннолетних граждан США имели активы в виде ценных бумаг. Всякие манипуляции, мошенничество с активами населения на рынке

\footnotetext{
${ }^{1}$ Данные Московской биржи.
} 
ценных бумаг в США считаются угрозой национальной безопасности и жестко преследуются в соответствии с федеральными правовыми нормами.

Наша страна только на стадии становления развитых рыночных отношений. У населения нет должного финансового мышления, адекватного рыночным отношениям, нет системы обучения финансовой грамотности.

«Основными чертами современного научного финансового мышления является умение не только мыслить важнейшими финансово-кредитными категориями (прибыль, налоги, проценты, доходы, расходы, кредит, фонд оплаты труда, амортизационные отчисления и т. д.), но и переводить их на конкретный язык реального бизнеса; умение считать бюджет домохозяйств и рационально его использовать. Отсутствие у большинства населения финансового мышления и образования приводит к огромному количеству просроченных кредитов и прочих неприятных явлений у населения» [5].

Этот процесс находится, по мнению автора, на начальном этапе. Обучение финансовой грамотности должно осуществляться комплексно, системно охватывать все регионы страны. Дисциплину «Финансовая грамотность» необходимо объективно включать в программы обучения, начиная с детских садов, включая и вузы.

Различные формы и методы обучения финансовой культуре организованы в Республике Бурятия, в том числе в Бурятском государственном университете.

В нашей стране разработана Стратегия развития фондового рынка Российской Федерации на период до 2020 г. Анализ целевых и фактических показателей развития фондового рынка показывает, что при разработке Стратегии были слишком оптимистичные прогнозы, не учитывающие риски на глобальном финансовом рынке. Анализ показывает, что количество розничных инвесторов на рынке ценных бумаг в 2008 г. по сравнению с 2020 г. должно было увеличиться в 25 раз с 0,8 млн до 20 млн соответственно. В 2017 г. число розничных инвесторов достигло всего 1,0 млн человек, за оставшиеся 3 года достичь целевых показателей сложно.

Таблица 1

Показатели развития фондового рынка Российской Федерации за период 2008-2020 годы ${ }^{1}$

\begin{tabular}{|l|c|c|c|}
\hline \multicolumn{1}{|c|}{ Показатель } & 2008 г. факт & 2017 г. факт & 2020 г. план \\
\hline Капитализация публичных компаний, трлн р. & 32,3 & 34 & 170 \\
\hline $\begin{array}{l}\text { Соотношение капитализации к валовому внут- } \\
\text { реннему продукту, \% }\end{array}$ & 97,8 & 39 & 104 \\
\hline $\begin{array}{l}\text { Количество розничных инвесторов на рынке } \\
\text { ценных бумаг, млн чел. }\end{array}$ & 0,8 & 1 & 20 \\
\hline
\end{tabular}

Фондовый рынок - это один из наиболее удобных и оптимальных способов получения финансовых ресурсов для непрерывных технологических изменений, расширения рынков сбыта продукции и в итоге повышения конкурентоспособности. Этот источник средств дешевле, чем банковский кредит: свобода от обя-

\footnotetext{
${ }^{1}$ Стратегия развития финансового рынка Российской Федерации на период до 2020 года: распоряжение Правительства РФ от 29.12.2008 №2043-р.
} 
Г. М. Осипова. Стратегия инвестиционного развития фондового рынка: теоретический аспект

зательств, процентов и т. д. Из данных табл. 1 видно, что капитализация публичных компаний далека от прогнозных и с большой доли вероятности не будет достигнута.

В целом Стратегия оказалась нереальной, весьма далекой от истины, от реалий сегодняшнего рынка, ни по капитализации публичных компаний, ни по соотношению капитализации к ВВП в процентах.

Автор полагает, что при разработке Стратегии развития фондового рынка были выбраны не самые удачные из существующих в теории типовых стратегий, на основе которых может разрабатываться, в частности, программа действий профессиональных участников фондового рынка в зависимости от ситуации на фондовом рынке и прогнозных сценариев ее изменения. Такими сценариями могут быть, например: аукционные, арбитражные, оптимизационные, рейтинговые, гибкого реагирования на изменения внешней среды, рыночного опережения и другие.

Во-первых, эти стратегии позволяют учитывать, что один и тот же актив может иметь различную цену на двух разных, в том числе географически удаленных рынках.

Во-вторых, стратегии позволяют определить целевую ориентированность портфеля ценных бумаг с точки зрения сочетания риска неопределенности, доходности и ликвидности вложений.

B-третьих, гибкое реагирование на изменение внешней среды. Оно заключается в том, что инвесторы (и крупные и мелкие), получая полную рыночную информацию, смогут на равных условиях использовать свои экономические и финансовые возможности для доступа на фондовый рынок.

В-четвертых, курсы акций подвержены частым колебаниям, которые не всегда адекватны реальным изменениям в делах хозяйствующих субъектов.

По нашему мнению, функционирование механизма стратегического развития инвестирования в ценные бумаги осуществляется не в отдельном временном промежутке, а непрерывно на протяжении всего инвестиционного процесса, начиная с момента формирования стратегических ориентиров и до полного завершения инвестиционного цикла. Но основные структурные составляющие функционирования механизма стратегического развития инвестирования в ценные бумаги должны представлять собой определенную последовательность тщательно проработанных действий набор процедур, мер, методов, анализа, направленных на достижение желаемой результативности. Механизм должен включать комплекс воздействия нормативно-правовых и административнораспорядительных актов, регулирующих деятельность индивидуальных и институциональных инвесторов, а также других субъектов инвестиционной сферы.

Выход из ситуации, сложившейся с реализацией Стратегии, лежит в сфере государственного регулирования, вернее, качестве и обоснованности разрабатываемых, принимаемых и утверждаемых программ. Необходимо при этом помнить, что когда прогнозируемые точки разнятся в десятки раз от реальных данных имеет место и социально-психологический аспект. Такое несоответствие фактических и целевых показателей укореняет в сознании населения догму о неэффективности системы разработки государственных программ, потенциальной невозможности привлечения широкого круга розничных инвесторов (табл. 1). 
Проведенное исследование показало необходимость учитывать, что суммарная стоимость российских компаний, отражаемая рынком ценных бумаг, является до сих пор несоответствующей реальной стоимости, то есть российский рынок по-прежнему существенно недооценен.

Отличие фондового рынка страны от зарубежных - это его сырьевая направленность. К сожалению, мы не видим движения инвестиционных инвесторов в сторону высокотехнологичных несырьевых отраслей.

Правительство России в 2015 г. для привлечения той части населения, которая традиционно предпочитает банковские депозиты, ввело в действие индивидуальные инвестиционные счета (ИИС). В июне 2017 г. это положение было закреплено внесением в Федеральный закон «О рынке ценных бумаг» ${ }^{1}$ в части увеличения максимальной суммы денежных средств, которую можно внести на ИИС в размере 1 млн р. вместо 400,0 тыс. р. (в течение календарного года). Максимальный размер инвестиционного вычета при этом не изменился и составляет $13 \%$ от суммы, внесенных на ИИС.

Для создания синергетического эффекта в функционировании фондового рынка необходимо оптимальное сочетание всех подсистем инфраструктуры фондового рынка. Адекватно должна работать информационная инфраструктура, позволяющая своевременно принимать действенные меры по предупреждению и пресечению спекулятивной и недобросовестной деятельности на фондовом рынке, в аспекте предоставления инсайдерской информации. Требуется усиление регулятивной инфраструктуры государства в области законодательства, а именно для обеспечения защиты прав инвесторов через разработку правил и установление требований к информации о лицах, являющихся конечными бенефициарами российских предприятий для снижения рисков и обеспечения спроса на эмитируемые финансовые инструменты.

Таким образом, фондовый рынок России - это растущий и продолжающий свое развитие в системе национальной экономики структура, все проблемы и недостатки будут изживаться только при условии комплексного и системного подхода. При этом население страны должно начать инвестировать в растущий рынок, у которого есть большие перспективы в будущем.

\section{Литература}

1. Ансофф И. Новая корпоративная стратегия. М., 2001. 416 с.

2. Крицкий О. Л., Бельснер О. А. Оптимизация портфеля финансовых инструментов // Финансы и кредит. 2013. № 36. С. 35-40.

3. Мескон М., Альберт М., Хедоури Ф. Основы менеджмента. М.: Дело, 2004. 594 с.

4. Осипова Г. М., Бухаева А. А. Современные тенденции формирования, противоречия и перспективы развития финансового анализа // Вестник Бурятского государственного университета. Экономика и менеджмент. 2018. № 2. С. 51-57.

5. Осипова Г. М. Потенциал учебных дисциплин в вузе для формирования финансового мышления обучающихся // Вестник Бурятского государственного университета. Педагогика. 2017. Вып. 7. С. 157-165.

\footnotetext{
${ }^{1} \mathrm{O}$ внесении изменений в Федеральный закон «О рынке ценных бумаг» и статью 3 Федерального закона «О саморегулируемых организациях в сфере финансового рынка: федер. закон от 20.12.2017 № 397-Ф3; О внесении изменений в статьи 10.2 и 20 Федерального закона «О рынке ценных бумаг»: федер. закон от 18.06.2017 № 123-ФЗ.
} 


\section{STRATEGY FOR INVESTMENT DEVELOPMENT OF THE STOCK MARKET: A THEORETICAL ASPECT}

\section{Geta M. Osipova}

Dr. Sci. (Econ.), Prof.,

Dorzhi Banzarov Buryat State University

24a Smolina St., Ulan-Ude 670000, Russia

E-mail: getaosipova@mail.ru

The article discusses the objective necessity of investment development of the stock market in a competition environment. We have studied the scientific views on the development of the "stock market" category in both foreign and domestic literature. It is revealed that the concept of "stock market", formulated by foreign authors is more consistent with the realities of a market economy, its uncertainty. This approach increase opportunities to enhance the role of a stock market in investment processes. An efficient economy is impossible without an optimally functioning stock market capable of attracting investment resources. We propose the measures to strengthen the regulatory infrastructure of the state through the development of rules and the establishment of requirements for information about the ultimate beneficiaries of Russian enterprises for the purposes of reducing risks and ensuring the demand for issued financial instruments, as well as to improve the taxation of services provided to financial market participants and enhance efficiency of dividend policy in order to attract domestic and foreign investors, including retail ones.

Keywords: stock market; investments; strategy; securities market; financial resources. 